\title{
Recomendaciones para el manejo de las infecciones respiratorias agudas bajas en menores de 2 años. Resumen ejecutivo
} Recommendations for the management of acute lower respiratory infections in children under 2 years of age. Executive summary

Comité Nacional de Neumonología, Comité Nacional de Infectología y

Comité Nacional de Medicina Interna

Coordinadores: Dra. Laura Moreno, Dr. Fernando Ferrero

http:/ /dx.doi.org/10.5546/aap.2015.373

Véase el texto completo en formato electrónico, en la sección "Consensos" del sitio web de la Sociedad Argentina de Pediatría http://www.sap.org.ar/index.php/contenidos/detalle/id/186

Las infecciones respiratorias agudas bajas (IRAB) aún representan una importante causa de morbimortalidad en nuestro medio. Desde la publicación de la anterior versión de esta guía (2006), hemos asistido a cambios que justifican su revisión.

En el apartado "Epidemiología", hemos resaltado el rol de los virus como agentes etiológicos de IRAB, particularmente de neumonía en menores de un año. Se han incorporado conocimientos sobre el rol de algunos virus menos conocidos, con el aporte de publicaciones locales de los últimos años. En relación con las bacterias, se han incorporado conceptos relacionados con el aumento de la prevalencia de Staphylococcus aureus meticilino resistente de la comunidad (SAMRAC) y la reemergencia de Bordetella pertussis.

En el documento, se pone énfasis

Correspondencia: Dra. Laura Moreno: lauramoreno@arnet. com.ar

Financiamiento: Ninguno.

Conflicto de intereses: Ninguno que declarar.

Recibido: 25-2-2015 Aceptado: 22-4-2015 de los enfoques diagnósticos y terapéuticos estandarizados actualmente en uso y se ha considerado la incorporación de nuevas tecnologías. Se ha señalado el oxígeno como el único recurso terapéutico de comprobada eficacia en esta patología. Se detallan las recomendaciones de su indicación y retiro, cuando corresponde su administración. De igual forma, se refuerza la necesidad de reflexionar sobre el uso inapropiado de antibióticos en una entidad de estricta etiología viral.

En el caso de la neumonía adquirida en la comunidad, cuando se sospecha etiología bacteriana, se respalda la vigencia del tratamiento empírico inicial en función de los agentes prevalentes. Sin embargo, dado que más de la mitad de los casos de neumonía de la comunidad en este grupo etario son de etiología viral, insistimos en la recomendación de implementar un uso más racional de antibióticos. En ese sentido, se ha revisado la evidencia sobre la utilidad que pueden tener algunos elementos clínicos y exámenes complementarios a la hora de tomar la decisión terapéutica (escala de predicción de bacterias).

Es probable que lo más importante que ofrezca este consenso en este rubro sea brindar a los profesionales 
el respaldo científico para no utilizar indiscriminadamente antibióticos en cuadros en los que no son necesarios, así como para tratar en forma ambulatoria y con antibióticos de primera línea (amoxicilina) a la gran mayoría de los pacientes con cuadros de neumonía de etiología presumiblemente bacteriana.

En relación con las supuraciones pleuropulmonares, se han revisado nuevas opciones de manejo, que incluyen el empleo de enzimas, y se ha resaltado el valor de lo utilizado hasta el momento.

Por último, se repasan las medidas de prevención específica disponibles, muchas de ellas incorporadas actualmente al Calendario Nacional de Vacunación, y el registro de factores de riesgo de padecer IRAB, que permiten orientar acciones de prevención inespecífica en la comunidad. Tanto la promoción de la lactancia materna como la adquisición de hábitos y de ambientes saludables (contaminantes domiciliarios, tabaquismo, etc.) se suman a las normas de control de infecciones hospitalarias y cuidados en el hogar.

En conclusión, este consenso ofrece recomendaciones para el manejo de los menores de 2 años con IRAB a partir de las mejores evidencias disponibles (que incluyen datos locales), factibles de ser implementadas en nuestro medio. Constituye un instrumento orientador de las decisiones de los profesionales y refuerza la importancia del uso racional de recursos.

Esperamos que este documento de la Sociedad Argentina de Pediatría respalde la actividad profesional diaria de todos los pediatras.

\section{REFERENCIAS}

1. Vidaurreta SM, Marcone DN, Ellis A, Ekstrom J, et al. Infección respiratoria aguda viral en niños menores de 5 años. Estudio epidemiológico en dos centros de Buenos Aires, Argentina. Arch Argent Pediatr 2011;109(4):296-304.

2. Argentina.MinisteriodeSaluddelaNación.Recomendaciones para la vigilancia, prevención y atención de las Infecciones Respiratorias Agudas en Argentina. Actualización marzo de 2014. Buenos Aires, 2014. [Consulta: 22 de abril de 2015]. Disponible en: http://www.msal.gov.ar/images/ stories / bes / graficos / 0000000476 cnt-Actualizacin $\% 20$ Recomendaciones \%20-\%20Infecciones\%20Respiratorias\%20 Agudas\%20Argentina\%20Marzo\%202014.pdf.

3. Ruvinsky RO, Regueira M, Fossati MS, Gagetti P, et al. Surveillance of invasive in Streptococcus pneumoniae in Argentina 1994-2007: changes in serotype distribution, serotype coverage of pneumococcal conjugate vaccines and antibiotic resistance. Journal of Pediatric Infectious Diseases 2010;5(3):263-9.

4. Gentile A, Romanin VS, Juárez MV, Lución MF, et al. Epidemiología de Bordetella pertussis en un hospital pediátrico. Arch Argent Pediatr 2014;112(1):26-32.

5. Moreno L, Krishnan JA, Duran P, Ferrero F. Development and validation of a clinical prediction rule to distinguish bacterial from viral pneumonia in children. Pediatr Pulmonol 2006;41(4):331-7.

6. Ralston SL, Lieberthal AS, Meissner HC, Alverson BK, et al. Clinical practice guideline: the diagnosis, management, and prevention of bronchiolitis. Pediatrics 2014;134(5):e1474-502.

Es muy difícil hacerle entender algo a alguien que se beneficia con el no entender. 